\title{
A Differential Effect of Lovastatin versus Simvastatin in Neurodevelopmental Disorders
}

\author{
Melania Muscas, ${ }^{1,2 *}$ Sang S. Seo, ${ }^{1,2 \star}$ Susana R. Louros, ${ }^{1,2 *}$ and ${ }^{-E m i l y ~ K . ~ O s t e r w e i l ~}{ }^{1,2}$
}

https://doi.org/10.1523/ENEURO.0162-20.2020

${ }^{1}$ Centre for Discovery Brain Sciences, University of Edinburgh, Edinburgh, EH8 9XD, United Kingdom and ${ }^{2}$ Simons Initiative for the Developing Brain, University of Edinburgh, Edinburgh, EH8 9XD, United Kingdom

Key words: autism; ERK; fmr1; fragile X; lovastatin

\section{Significance Statement}

The statin drug lovastatin normalizes excessive protein synthesis and thereby ameliorates pathologic changes in animal models of fragile X syndrome (FX), the most commonly identified genetic cause of autism. Recently, we compared the efficacy of lovastatin to the more potent and brain-penetrant drug simvastatin for correcting phenotypes in the $F m r^{-1 y}$ mouse (Muscas et al., 2019). Surprisingly, we find simvastatin worsens excessive protein synthesis and has no impact on audiogenic seizures (AGS) in Fmr1 ${ }^{-1 / y}$ mice, suggesting it does not work in a similar fashion to lovastatin. A recent commentary by Ottenhoff et al. (2020) suggests that differences in dose and/or study design might account for our results. Here, we discuss the points raised by Ottenhoff et al. as well as the evidence supporting a therapeutic role for lovastatin versus simvastatin. We conclude that differences between lovastatin and simvastatin warrant careful consideration with respect to the treatment of neurodevelopmental disorders.

Therapeutic strategies that reduce protein synthesis have shown efficacy in reducing pathologic brain phenotypes in fragile X syndrome (FX; Stoppel et al., 2017; Protic et al., 2019). In the FX (Fmr1 $\left.{ }^{-1 /}\right)$ mouse model, lovastatin reduces the activation of Ras and downstream extracellular regulated-kinase (ERK) signaling, thereby normalizing protein synthesis and correcting changes in synaptic plasticity, neuronal hyperexcitability, epileptogenesis, and learning (Osterweil et al., 2013; Sidorov et al., 2014; Table 1). In the $F m r 1^{-1 / y}$ rat model, early

Received April 28, 2020; accepted June 16, 2020; First published July 10, 2020.

The authors declare no competing financial interests.

Author contributions: E.K.O. designed research; M.M., S.S.S., and S.R.L. performed research; E.K.O. wrote the paper.

This work was supported by the Wellcome Trust/Royal Society (Sir Henry Dale Fellowship 104116/Z/14/Z), the Medical Research Council Grant MRC MR/M006336/1, and the Simons Initiative for the Developing Brain (SIDB).

*M.M., S.S.S., and S.R.L. contributed equally to this work.

Acknowledgements: We thank Owen Dando for helpful discussion regarding data analysis and all members of the Osterweil lab for helpful discussions.

Correspondence should be addressed to Emily K. Osterweil at emily. osterweil@ed.ac.uk.

https://doi.org/10.1523/ENEURO.0162-20.2020

Copyright () 2020 Muscas et al.

This is an open-access article distributed under the terms of the Creative Commons Attribution 4.0 International license, which permits unrestricted use, distribution and reproduction in any medium provided that the original work is properly attributed. administration of lovastatin prevents emergence of plasticity deficits and learning deficiencies later in development (Asiminas et al., 2019). In recent work, we tested whether the structurally similar drug simvastatin could correct core phenotypes of excessive hippocampal protein synthesis and audiogenic seizures (AGS) in the $\mathrm{Fmr1}^{-1}$ ${ }^{y}$ mouse (Muscas et al., 2019). The motivation for testing simvastatin versus lovastatin is a two- to four-fold increase in potency, increased brain penetrance, and wider availability in Europe (Schachter, 2005). However, simvastatin has not been tested in any model of FX, and preclinical evidence of efficacy was required before incurring the significant cost of a clinical trial. This is particularly relevant for simvastatin, which has been tested for the treatment of neurofibromatosis type 1 (NF1), a neurodevelopmental disorder characterized by excessive RasERK signaling. Early studies in the $\mathrm{Nf1+/}$ - mouse showed a significant correction of several brain phenotypes with lovastatin (Li et al., 2005). Assuming the mechanisms for reversing pathologic changes were identical for lovastatin and simvastatin, clinical trials were initiated for simvastatin in NF1 despite the absence of animal model studies. To date, three randomized placebo-controlled clinical trials for simvastatin in NF1 have failed to show a significant improvement in primary outcome measures (Krab et al., 2008; van der Vaart et al., 2013; Stivaros et al., 2018; Table 2). 
Table 1: Animal model studies of lovastatin and simvastatin in neurodevelopmental disorders

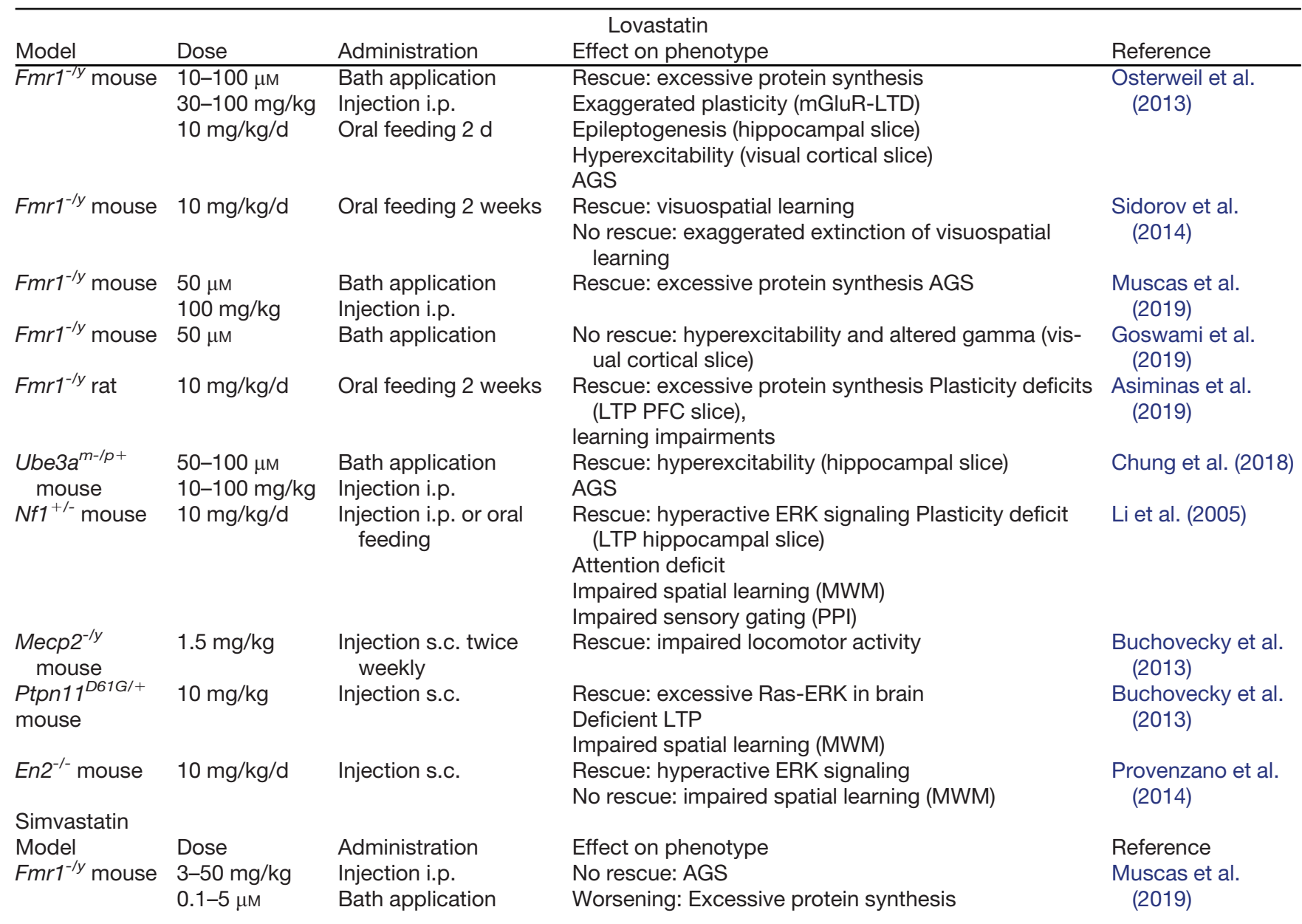

Studies using animal models of neurodevelopmental disorders have tested the impact of lovastatin on multiple phenotypes. Ours is the only study of simvastatin in a neurodevelopmental animal model.

i.p.: intraperitoneal, s.c.: subcutaneous, mGluR-LTD: metabotropic glutamate receptor stimulated long-term depression, LTP: long-term potentiation, PFC: prefrontal cortex, ERK: extracellular-regulated kinase, MWM: Morris Water Maze, PPI: pre-pulse inhibition.

To our surprise, the comparison of lovastatin and simvastatin in the FX mouse model revealed significant differences. While lovastatin reduces protein synthesis in $\mathrm{Fmr1}^{-1 / y}$ hippocampus to wild-type (WT) levels, simvastatin resulted in a significant increase in protein synthesis in both genotypes (Fig. 1A). In contrast to lovastatin, simvastatin does not reduce ERK activation in $\mathrm{Fmr1}^{-/ y}$ hippocampus, which is a key driver of the excess protein synthesis phenotype (Osterweil et al., 2010; Muscas et al., 2019). Moreover, simvastatin does not reduce the incidence of AGS in $\mathrm{Fmr1}^{-/ y}$ mice, even when administered at a limiting high dose (Fig. 1B). In contrast, lovastatintreated cohorts show a significant reduction in seizure incidence, consistent with previous work (Fig. 1C; Osterweil et al., 2013). From these results, we conclude that lovastatin and simvastatin do not work in a similar fashion with respect to FX models and suggest caution should be used when assuming these compounds are interchangeable. Our results have been discussed in a recent commentary by Ottenhoff et al. (2020), who have been involved in clinical trials with simvastatin for the treatment of NF1 (Krab et al., 2008; van der Vaart et al., 2013; Stivaros et al., 2018; Ottenhoff et al., 2020). The authors raise points regarding our study design, suggesting differences in dose and/or study design might account for the failure of simvastatin to correct $F m r 1^{-1 y}$ phenotypes. Here, we discuss these points and examine the evidence supporting lovastatin versus simvastatin for the treatment of neurodevelopmental disorders.

\section{Different Actions on Protein Synthesis}

Multiple treatments that normalize excess protein synthesis also ameliorate epileptogenic and behavioral phenotypes in FX models (Dölen et al., 2007; Liu et al., 2011; Gkogkas et al., 2014; Gantois et al., 2017; Stoppel et al., 2017). To investigate whether simvastatin corrects the excessive protein synthesis phenotype in the $\mathrm{Fmr}^{-/ y}$ mouse, we used a metabolic labeling assay in hippocampal slices that has been employed in previous studies (Osterweil et al., 2010). As the potency of simvastatin is two- to four-fold that of lovastatin (Schaefer et al., 2004), 
Table 2: Human studies of lovastatin and simvastatin in neurodevelopmental disorders

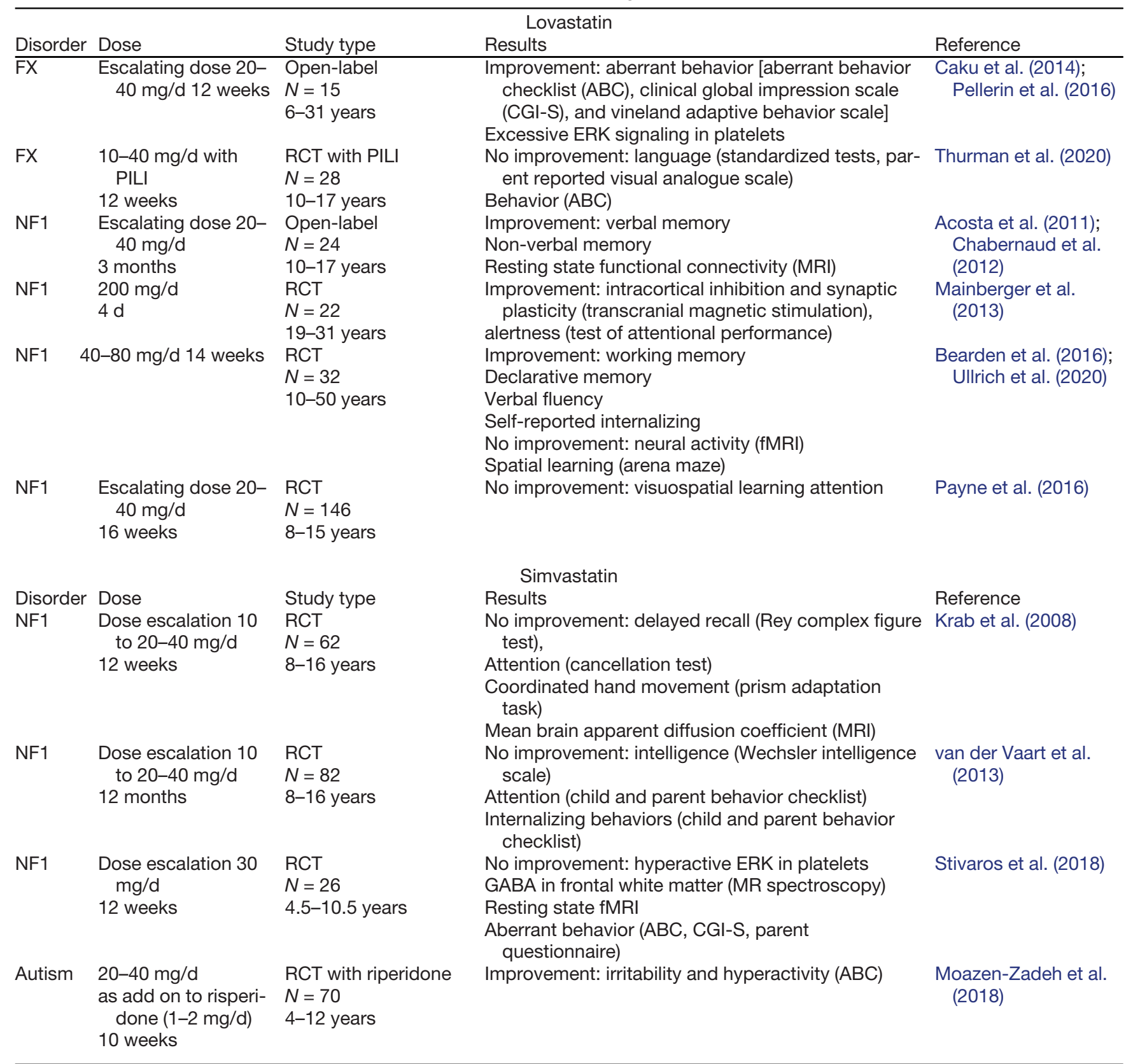

Lovastatin and simvastatin have been tested in clinical trials for FX and NF1, with varying outcomes.

RCT: randomized placebo-controlled trial; ABC: aberrant behavior checklist, CGI-S: clinical global impression scale, MRI: magnetic resonance imaging, ERK: extracellular-regulated kinase, GABA: $\gamma$-Aminobutyric acid.

we chose a starting dose of $5 \mu \mathrm{M}$, which is half the $10 \mu \mathrm{M}$ starting dose of lovastatin used in previous work (Osterweil et al., 2013). Remarkably, this relatively modest dose of simvastatin caused a $50-60 \%$ increase in protein synthesis in both WT and Fmr1 ${ }^{-1 y}$ slices, dramatically worsening the protein synthesis phenotype (Fig. 1A; Muscas et al., 2019). Given these results, we reasoned that increasing concentration would not only be ineffective, it would have deleterious consequences for both WT and $F m r 1^{-1 / y}$ hippocampus. Instead, we tested whether a lower dose range of $0.1-0.5 \mu \mathrm{m}$ simvastatin might mitigate potential off-target effects and reduce the protein synthesis phenotype. Unfortunately, increased protein synthesis continued to be seen in slices treated at these lower doses (Fig. 1A). In contrast, WT/Fmr1 ${ }^{-l y}$ littermates treated with $50 \mu \mathrm{M}$ lovastatin resulted in the expected decrease in protein synthesis in $\mathrm{Fmr1}^{-1 /}$ slices.

Looking at these results, it is clear that under conditions where lovastatin normalizes protein synthesis in the $\mathrm{Fmr}^{-1 / y}$ hippocampus, simvastatin causes a dramatic worsening of this core phenotype. Regarding these results, Ottenhoff et al. state the following: 
A

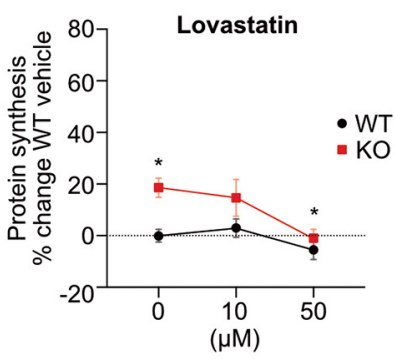

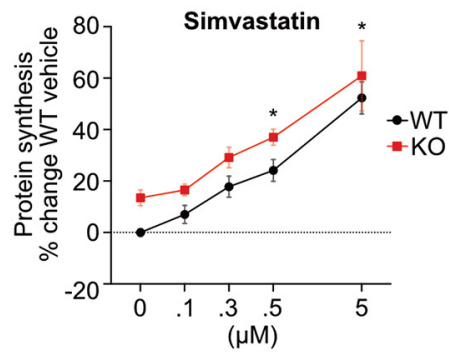

B

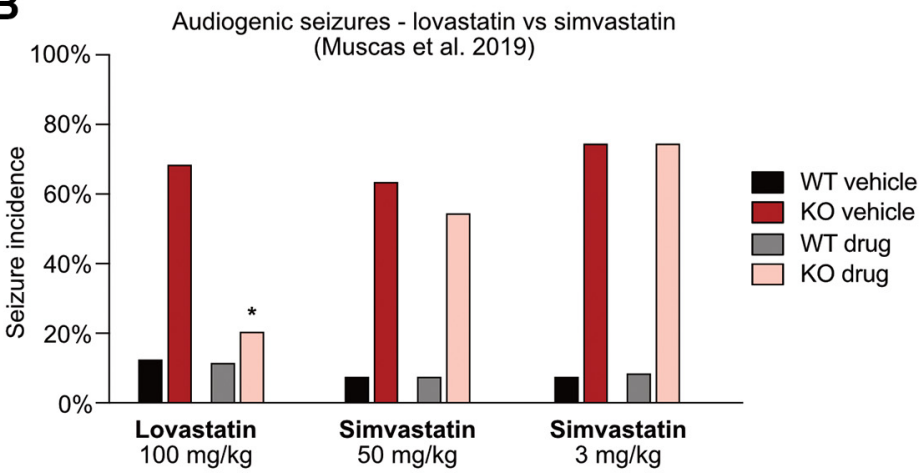

C Audiogenic seizures - lovastatin vs simvastatin

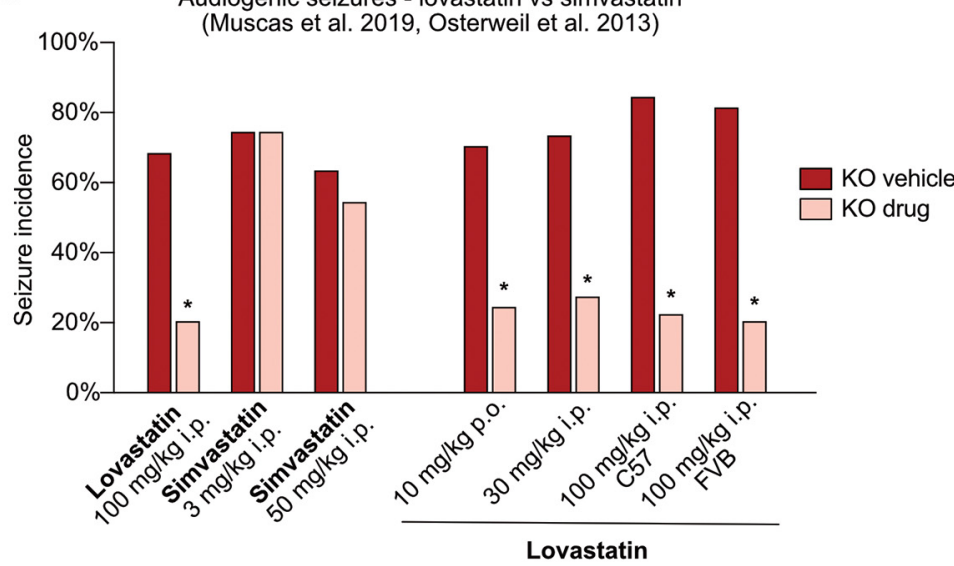

Figure 1. Lovastatin, not simvastatin, corrects fragile X phenotypes. A, Data from Osterweil et al. (2013) and Muscas et al. (2019) were combined and re-analyzed. Metabolic labeling was performed on hippocampal slices prepared from WT/Fmr $1^{-/ y}$ littermates as previously described. A dose-response curve shows lovastatin corrects excess protein synthesis in the $F m r 1^{-/ y}$ hippocampus at 50 $\mu \mathrm{M}$ (two-way repeated measures mixed-model ANOVA treatment $p=0.0052$, genotype $p=0.0006$, genotype $\times$ treatment $p=0.0438$; Sidak's WT veh vs KO veh $* p=0.0021$, KO veh vs KO $50 * p=0.0014)$. In contrast, simvastatin significantly raises protein synthesis in a dose-dependent manner in both $\mathrm{Fmr1}^{-1 /}$ and WT hippocampus (two-way repeated measures mixed-model ANOVA treatment $p<0.0001$, genotype $p=0.0005$, genotype $\times$ treatment $p=0.9754$, Sidak's WT veh vs WT $0.5 * p=0.0120$, WT veh vs WT 5 $* p<0.0001$, KO veh vs KO $0.5 * p=0.0157$, KO veh vs KO $5 * p<0.0001$ ). B, Data re-plotted from Muscas et al. (2019; Extended Data Figure 1-1). AGS assays show that acute injection of $100 \mathrm{mg} / \mathrm{kg}$ lovastatin significantly reduces the incidence of seizures in $\mathrm{Fmr}^{-/ y}$ mice versus vehicle control (Fisher's exact test $\left.* p=0.0136\right)$. Conversely, neither an equipotent dose of $50 \mathrm{mg} / \mathrm{kg}$ simvastatin (Fisher's exact test $p=0.6968$ ) nor a lower $3 \mathrm{mg} / \mathrm{kg}$ dose significantly (Fisher's exact test $p>0.999$ ) impacts the incidence of seizures in the $F m r 1^{-1 y}$ mouse. C, AGS results from Muscas et al. (2019) and Osterweil et al. (2013) show that although simvastatin fails to reduce seizures, lovastatin significantly reduces seizures when given at $10 \mathrm{mg} / \mathrm{kg}$ orally for $2 \mathrm{~d}$, $30 \mathrm{mg} / \mathrm{kg}$ injection (intraperitoneal), or $100 \mathrm{mg} / \mathrm{kg}$ injection (intraperitoneal) in $\mathrm{Fmr}^{-1 /}$ mice on both C57BL6 and FVB background strains (Fisher's exact test: $10 \mathrm{mg} / \mathrm{kg} * p=0.003,30 \mathrm{mg} / \mathrm{kg} * p=0.041,100 \mathrm{mg} / \mathrm{kg} \mathrm{C57} * p=0.005,100 \mathrm{mg} / \mathrm{kg} \mathrm{FVB} * p=0.005 ;$ Extended Data Figs. 1-2, 1-3). 
"the most surprising finding of the study by Muscas and colleagues is the finding that simvastatin treatment at low dose actually worsened the Fmr1 phenotype by further increasing protein synthesis rates. (...) For the follow-up of these trials it would be of great importance to know if a comparable (low) dose of lovastatin (below the doses needed to inhibit ERK) would have a similar negative effect on this phenotype, especially since the dose that can be safely used in clinical trials is much lower than the in vivo dose used in this study."

We note that dose-response studies have in fact shown that lovastatin decreases protein synthesis at 1, 10, and $20 \mu \mathrm{M}$ in cultured neuroblasts (Santa-Catalina et al., 2008). In hippocampal slices, we have established that a lower dose of $10 \mu \mathrm{m}$ lovastatin does not cause a significant reduction in protein synthesis; however, it certainly does not cause the dramatic increase seen with simvastatin (Fig. 1A; Osterweil et al., 2013). In contrast, the impact of simvastatin on protein synthesis in neuronal cells has not been determined. The study cited by Ottenhoff et al. describes experiments performed in a muscle-derived C2C12 cell line, and it is not unreasonable to expect that the response in the nervous system will differ (Tuckow et al., 2011). Indeed, simvastatin has been shown to have a number of brain-specific effects that could contribute to the rise in protein synthesis, including a stimulation of neurotrophin release and augmentation of the expression and activation of NMDA-type glutamate receptors (NMDARs; Parent et al., 2014; Roy et al., 2015; Chen et al., 2016). With respect to the latter, acute application of simvastatin has been shown to enhance surface expression and current flow through NMDARs in hippocampal slices, increasing the magnitude of long-term potentiation (LTP; Parent et al., 2014; Chen et al., 2016). The changes in calcium influx and downstream signaling that are associated with NMDAR activation could contribute to the rise of protein synthesis we observe. In contrast, lovastatin has been shown to downregulate the GluN2B subunit of the NMDAR and thereby reduce associated signaling (Huo et al., 2014). This opposing action on NMDARs may contribute to the differential action on protein synthesis in hippocampal slices.

However, it should be noted that longer treatments with simvastatin, lovastatin, and other statins reduce the production of cholesterol needed to stabilize NMDARs at the cell surface, ultimately causing a mild reduction in activity (Zacco et al., 2003; Ponce et al., 2008; Huo et al., 2014; McFarland et al., 2014). Therefore, longer-term experiments testing protein synthesis at multiple timepoints post simvastatin treatment are needed to determine whether changes in NMDAR activity are involved. What we can conclude for now is that the differential impact of lovastatin and simvastatin on basal protein synthesis is striking and should be investigated in follow-up studies.

\section{Different Actions on ERK}

Statins inhibit the 3-hydroxy-3-methylglutaryl coenzyme A (HMG-CoA) reductase pathway that produces both cholesterol and isoprenoid intermediates, which are important substrates for the posttranslational modification and activation of many proteins (Liao, 2005; Ling and TejadaSimon, 2016; Nürenberg and Volmer, 2012). Lovastatin has been shown to inhibit the Ras farnesylation required for membrane association and subsequent activation of the ERK pathway (Schafer et al., 1989; Mendola and Backer, 1990; Li et al., 2005). In our comparison study, we find that the low doses of simvastatin that raise protein synthesis have no significant impact on ERK activation in the $F m r 1^{-/ y}$ hippocampus (Muscas et al., 2019). Ottenhoff et al. argue that this result conflicts with previous work that shows "like lovastatin, simvastatin has been shown to decrease ERK signaling." We note that the simvastatin dose used in our study is low because of the impact of higher doses on protein synthesis, and it may be that higher doses of simvastatin ultimately show an inhibitory effect on ERK. However, it is important to consider that the cited studies either do not measure ERK (Guillén et al., 2004; Ghittoni et al., 2006; Ghosh et al., 2009) or show that simvastatin reduces ERK signaling in non-neuronal cells only when Ras-ERK is hyperstimulated, but not under basal conditions (Fürst et al., 2002; Miura et al., 2004; Ghittoni et al., 2005; Khanzada et al., 2006; Ogunwobi and Beales, 2008; Sundararaj et al., 2008; Kang et al., 2009; Chen et al., 2010; Lee et al., 2011; Takayama et al., 2011).

Unlike simvastatin, lovastatin has been shown to reduce basal Ras-ERK signaling in the absence of activation (Santa-Catalina et al., 2008; Osterweil et al., 2013). This point is particularly relevant to the protein synthesis phenotype in FX, which is not because of a hyperactivation of the ERK pathway but rather a hypersensitive response to normal levels of ERK signaling (Osterweil et al., 2010). It is also important to point out that clinical studies of platelets isolated from simvastatin-treated NF1 patients show no significant reduction in basal ERK activation (Stivaros et al., 2018), whereas those isolated from lovastatin-treated FX patients exhibit a robust reduction in ERK signaling that is correlated with treatment efficacy (Pellerin et al., 2016). Future studies examining the mechanistic differences between these statins could be particularly valuable for understanding the impact on neurologic phenotypes.

\section{Different Actions on AGS}

The AGS phenotype has been used to test multiple potential pharmacological strategies that have moved on to clinical investigation in FX, including lovastatin (Yan et al., 2005; Liu et al., 2012; Busquets-Garcia et al., 2013; Osterweil et al., 2013; Gkogkas et al., 2014; Gantois et al., 2017; Stoppel et al., 2017). In Muscas et al. (2019), we compared acute injection of $100 \mathrm{mg} / \mathrm{kg}$ lovastatin to an equipotent dose of $50 \mathrm{mg} / \mathrm{kg}$ simvastatin. The results show a clear reduction in seizure incidence and severity with lovastatin, and no effect of simvastatin (Fig. 1B). Although Ottenhoff et al. argue "there is no experiment in which lovastatin and simvastatin are compared at the same dose (and with the same vehicle)," the differential potency of these drugs has been well established (Schachter, 2005). If the question is whether there is an equivalent impact of these drugs, we would argue equivalent potency is a key point. Moreover, our attempts to increase simvastatin to $100 \mathrm{mg} / \mathrm{kg}$ revealed deleterious side 
Table 3: Reordered comparisons reveal correct $p$ values for Tukey's post-hoc tests

\begin{tabular}{|c|c|c|c|c|c|c|}
\hline \multirow[b]{2}{*}{ Test } & \multicolumn{3}{|c|}{ Ottenhoff et al. (incorrect order) } & \multicolumn{3}{|c|}{ Muscas et al. (corrected order) } \\
\hline & Estimate & $z$ value & $p$ value & Estimate & $z$ value & $p$ value \\
\hline WT, simvalow vs Veh & -0.4700 & -0.366 & 0.9997 & -0.2288 & -0.196 & 1.0000 \\
\hline WT, simvalow vs lova & -0.3159 & -0.271 & 0.9999 & -0.3830 & -0.297 & 0.9999 \\
\hline WT, simvahigh vs lova & -0.2288 & -0.196 & 1.0000 & -0.4700 & -0.366 & 0.9997 \\
\hline WT, simvalow vs simvahigh & -0.0870 & -0.059 & 1.0000 & -0.0870 & -0.059 & 1.0000 \\
\hline $\mathrm{KO}$, simvahigh vs Veh & 2.3979 & 2.573 & 0.0932 & -0.6200 & -0.897 & 0.9607 \\
\hline $\mathrm{KO}$, simvalow vs lova & -0.6200 & -0.897 & 0.9607 & 2.3979 & 2.573 & 0.0932 \\
\hline KO, simvahigh vs lova & 0.2963 & 0.397 & 0.9995 & 1.4816 & 1.666 & 0.5570 \\
\hline $\mathrm{KO}$, simvalow vs simvahigh & -0.9163 & -1.017 & 0.9288 & -0.9163 & -1.017 & 0.9288 \\
\hline
\end{tabular}

The regression model R script used by Ottenhoff et al. (2020) assigns different functions to set up the regression model matrix ("unique") versus the Tukey's contrast matrix ("tables"). This results in different order of groups for the two matrices, which results in assignment of different headings to the test results. An altered version of the script with the factors level set in the same order for the model matrix and contrast matrix shows the correct Tukey's test results (see Extended Data Figure 1-3). Estimate and $z$ value are multiplied by -1 to reflect the corresponding tests headings. Reversed values are italicized and the corrected $p$ values reported by Ottenhoff are in bold.

effects that would have made it impossible to make a meaningful comparison.

Ottenhoff et al. bring up the important point that "the dose in which a particular drug rescues a phenotype in animal model does not always translate into a clinically applicable and safe dose in humans." In our study, we compared acute injections of relatively high doses of lovastatin and simvastatin because of the rapid action of these higher doses on the AGS phenotype (Osterweil et al., 2013). However, we also tested a lower dose of $3 \mathrm{mg} /$ $\mathrm{kg}$ that is consistent with the dose given to humans according to standard calculations (Nair and Jacob, 2016; Fig. 1B). Similar to the higher dose of simvastatin, the $3 \mathrm{mg} / \mathrm{kg}$ dose also failed to reduce seizures in the $F m \mathrm{r}^{-/ y}$ mouse. In contrast, a range of lovastatin doses correct the AGS phenotype in $F m r 1^{-/ y}$ mice including a 2-d $10 \mathrm{mg} / \mathrm{kg}$ oral administration that is consistent with a human dose (Fig. 1C). This correction of AGS with lovastatin is seen whether Fmr1 ${ }^{-/ y}$ mice are bred on the FVB or C57BL6 background strains (Osterweil et al., 2013). Ottenhoff et al. argue "if a behavioral rescue is observed in young mice (e.g., the rescue of seizures in Fmr1 mice was performed on P18-P29 mice; Osterweil et al., 2013; Muscas et al., 2019), it is important to investigate if such a rescue is still observed when the brain has fully matured." We note that multiple studies in mouse and rat models of FX and other neurodevelopmental disorders have shown that lovastatin corrects pathologic phenotypes over a range of animal ages, including adults (Table 1). In contrast, beyond our study, there is no previous work examining simvastatin in any animal model of neurodevelopmental disorders including the $\mathrm{Nf1+} /-$ mouse.

\section{Study Design}

From the side-by-side experiments comparing lovastatin versus simvastatin, we conclude there are differences in mechanism and efficacy that should be considered and further investigated in additional animal model studies. Ottenhoff et al. question whether the differences we report are in fact significant, stating "the drugs should not

Table 4: Regression model of AGS incidence and severity shows significant treatment effect in lovastatin versus simvastatin groups

\begin{tabular}{|c|c|c|c|}
\hline Regression model & Genotype effect & Treatment effect & Interaction effect \\
\hline Logistical regression, type 2 ANOVA (Muscas et al., 2019) & $p=6.22 \times 10^{-12}$ & $p=0.053$ & $p=0.263$ \\
\hline $\begin{array}{l}\text { Logistical regression (Muscas et al., 2019) + all lovastatin groups } \\
\text { from Osterweil et al. (2013) }\end{array}$ & $p<2.2 \times 10^{-16}$ & $p=8.08 \times 10^{-9}$ & $p=0.4$ \\
\hline
\end{tabular}

Re-running the logistical regression comparing lovastatin and simvastatin treatments using a type 2 ANVOA shows a non-significant trend towards an effect of treatment. Adding data from the FVB $100 \mathrm{mg} / \mathrm{kg}$ lovastatin group originally published in Osterweil et al. (2013) shows a significant treatment effect either when kept separate or when collapsed into the existing lovastatin group. Adding data from additional lovastatin treatment groups from C57BL6 cohorts from Osterweil et al. $(2013 ; 10,30$, and $100 \mathrm{mg} / \mathrm{kg})$ further increases the significance of the treatment effect. As the interaction of genotype and treatment does not reach significance using this model, it may be that lovastatin corrects seizures in both WT and Fmr $1^{-1 /}$ mice equally; however, the low number of animals have seizures in the WT groups makes this difficult to assess. To compare lovastatin versus simvastatin treatment groups, a multinomial regression model of seizure severity scores with genotype and treatment effect was performed in R using the multinom function in the nnet package (see Extended Data Figure 1-3). 
only be tested side-by-side as interleaved experiments, they should also directly be compared with each other using a statistical analysis that tests for a main effect of treatment, and if significant, followed by a post hoc analysis to compare the drugs." Our experimental design compares lovastatin and simvastatin to matched vehicle groups, rather than directly to one another, because different concentrations of dimethylsulfoxide (DMSO) were needed for each drug. The blinded comparison of drug groups to counter-balanced vehicle controls is considered good practice by multiple authorities on experimental design for laboratory animals (Festing and Altman, 2002).

In order to evaluate the effects of lovastatin and simvastatin on seizure incidence, we used a Fisher's exact test that allows for comparisons between small $(<50)$ nominal (yes/no) datasets, consistent with previous AGS studies (Pacey et al., 2009; Osterweil et al., 2010, 2013; Henderson et al., 2012; Michalon et al., 2012; Ronesi et al., 2012; Gross et al., 2015; Thomson et al., 2017). We find a significant difference in seizure incidence between vehicle and lovastatin-treated $\mathrm{Fmr1}^{-1 / y}$ mice (48\%, $p=0.0136$ ), but not vehicle versuslow-dose simvastatin $(0 \%, p>0.999)$ or vehicle versushigh-dose simvastatin ( $9 \%, p=0.6968$; Fig. 1C). However, Ottenhoff et al. suggest that fitting our data to a logistic regression model is a better approach for determining global effects of treatment and genotype in all groups. They go on to fit our data to a model and state that it "shows a trend for a main effect of treatment $\left(\chi^{2}(6)=12 ; p=0.07\right)$, but not for the interaction between genotype and treatment $\left(\chi^{2}(4)=4\right.$; $p=0.3$ ). When performing a post-hoc Tukey's test, neither the Fmr1-lovastatin versus Fmr1 'low dose' of simvastatin $(p=0.96)$ nor the Fmr1-lovastatin versus Fmr1-'high dose' of simvastatin treatment $(p>0.99)$ are significantly different from each other. Hence, despite the fact that the lovastatin dose was 2-30 fold higher than simvastatin dose, it does not seem to perform significantly better than simvastatin in this seizure assay."

To investigate this issue, we examined the $R$ script used to run the logistic regression model (shared by Ottenhoff et al.). Our analysis revealed a script error that led to the wrong reporting of $p$ values from the Tukey's post hoc tests. Running a corrected script shows lower $p$ values for the comparisons of lovastatin and simvastatin in $F m r 1^{-1 y}$ mice than originally published (Table 3). Additionally, Ottenhoff et al. run a type 1 ANOVA that assumes an interaction between genotype and treatment, which we do not claim (nor can we with such a low incidence of seizures in WT). Re-running the logistic regression using a type 2 ANOVA that does not assume an interaction shows a trend toward a main effect of treatment, though this does not reach significance $(p=0.053)$. However, our original study was not powered to directly compare treatment groups, and we therefore investigated whether adding an additional treatment group would change the outcome of this analysis. In the original study testing lovastatin in $\mathrm{Fmr1}^{-1 /}$ mice, multiple drug doses were tested in both FVB and C57BL6 background strains (Osterweil et al., 2013; Fig. 1C). After adding the data from the FVB group treated with $100 \mathrm{mg} / \mathrm{kg}$ lovastatin in this study, we re-ran the logistic regression and find a significant effect of treatment $(p=0.00021)$. When both lovastatin groups are collapsed, the significance of this effect increases $\left(p=9.22 \times 10^{-5}\right)$. Adding all lovastatin groups from Osterweil et al. (2013) increases the significance further $\left(p=8.08 \times 10^{-9}\right.$; Table 4). Therefore, the logistic regression identifies the difference in treatment when given a dataset of sufficient size. Moreover, we find that a multinominal regression model that examines seizure severity scores reveals a significant treatment effect, even when applied to the original dataset from Muscas et al. (2019; $p=0.033$; Table 4). The important conclusion is that whether our results are analyzed directly or fit to a more complex model, they show that lovastatin corrects the AGS phenotype in $F m r 1^{-1 y}$ mice, and simvastatin does not.

\section{Future Considerations}

Our studies in $F m r 1^{-/ y}$ animal models show promising results for lovastatin that are not seen with simvastatin. However, it is important to note that the role of statins in the treatment of fragile $X$ and other neurodevelopmental disorders will ultimately depend on large scale doubleblind placebo-controlled trials. In the case of lovastatin, the results from double-blind placebo-controlled trials for NF1 are mixed, with one showing a significant improvement in verbal and nonverbal memory (Bearden et al., 2016), and another showing no significant effect on visuospatial learning and attention (Payne et al., 2016). In FX, a recent small-scale double-blind trial showed no additional effect of lovastatin on parent implemented language intervention (Thurman et al., 2020). For simvastatin, three randomized placebo controlled clinical trials have failed to show efficacy in NF1 (Table 2). At present, our study represents the only exploration of simvastatin in an animal model of neurodevelopmental disorders. We agree with Ottenhoff et al. that "importance of looking at effective dosing ranges, and more detailed (in vivo) pharmacological studies in animal models should be performed to elucidate the dose-dependency of therapeutic benefit." Whether simvastatin shows benefits in FX or other models using a specific dosing regimen or alternative behavioral assays is an open question that would be very informative for future clinical studies. What is clear from our initial work is that there are significant differences between the action of lovastatin and simvastatin on brain function that warrant further attention.

\section{References}

Acosta MT, Kardel PG, Walsh KS, Rosenbaum KN, Gioia GA, Packer RJ (2011) Lovastatin as treatment for neurocognitive deficits in neurofibromatosis type 1: phase I study. Pediatr Neurol 45:241-245.

Asiminas A, Jackson AD, Louros SR, Till SM, Spano T, Dando O, Bear MF, Chattarji S, Hardingham GE, Osterweil EK, Wyllie DJA, Wood ER, Kind PC (2019) Sustained correction of associative learning deficits after brief, early treatment in a rat model of fragile X syndrome. Sci Transl Med 11:eaao0498.

Bearden CE, Hellemann GS, Rosser T, Montojo C, Jonas R, Enrique N, Pacheco L, Hussain SA, Wu JY, Ho JS, McGough JJ, Sugar CA, Silva AJ (2016) A randomized placebo-controlled lovastatin 
trial for neurobehavioral function in neurofibromatosis I. Ann Clin Transl Neurol 3:266-279.

Buchovecky CM, Turley SD, Brown HM, Kyle SM, McDonald JG, Liu B, Pieper AA, Huang W, Katz DM, Russell DW, Shendure J, Justice MJ (2013) A suppressor screen in Mecp2 mutant mice implicates cholesterol metabolism in Rett syndrome. Nat Genet 45:1013-1020.

Busquets-Garcia A, Gomis-González M, Guegan T, Agustín-Pavón C, Pastor A, Mato S, Pérez-Samartín A, Matute C, de la Torre R, Dierssen M, Maldonado R, Ozaita A (2013) Targeting the endocannabinoid system in the treatment of fragile $X$ syndrome. Nat Med 19:603-607.

Caku A, Pellerin D, Bouvier P, Riou E, Corbin F (2014) Effect of lovastatin on behavior in children and adults with fragile $X$ syndrome: an open-label study. American journal of medical genetics Part A 164a:2834-2842.

Chabernaud C, Mennes M, Kardel PG, Gaillard WD, Kalbfleisch ML, Vanmeter JW, Packer RJ, Milham MP, Castellanos FX, Acosta MT (2012) Lovastatin regulates brain spontaneous low-frequency brain activity in neurofibromatosis type 1. Neurosci Lett 515:28-33.

Chen T, Zhang B, Li G, Chen L, Chen L (2016) Simvastatin enhances NMDA receptor GluN2B expression and phosphorylation of GluN2B and GluN2A through increased histone acetylation and Src signaling in hippocampal CA1 neurons. Neuropharmacology 107:411-421.

Chen YJ, Chen P, Wang HX, Wang T, Chen L, Wang X, Sun BB, Liu DS, Xu D, An J, Wen FQ (2010) Simvastatin attenuates acrolein-induced mucin production in rats: involvement of the Ras/extracellular signalregulated kinase pathway. Int Immunopharmacol 10:685-693.

Chung L, Bey AL, Towers AJ, Cao X, Kim IH, Jiang YH (2018) Lovastatin suppresses hyperexcitability and seizure in Angelman syndrome model. Neurobiol Dis 110:12-19.

Dölen G, Osterweil E, Rao BS, Smith GB, Auerbach BD, Chattarji S, Bear MF (2007) Correction of fragile $X$ syndrome in mice. Neuron 56:955-962.

Festing MF, Altman DG (2002) Guidelines for the design and statistical analysis of experiments using laboratory animals. ILAR J 43:244-258.

Fürst J, Haller T, Chwatal S, Wöll E, Dartsch PC, Gschwentner M, Dienstl A, Zwierzina H, Lang F, Paulmichl M, Ritter M (2002) Simvastatin inhibits malignant transformation following expression of the Ha-ras oncogene in NIH 3T3 fibroblasts. Cell Physiol Biochem 12:19-30.

Gantois I, Khoutorsky A, Popic J, Aguilar-Valles A, Freemantle E, Cao R, Sharma V, Pooters T, Nagpal A, Skalecka A, Truong VT, Wiebe S, Groves IA, Jafarnejad SM, Chapat C, McCullagh EA, Gamache K, Nader K, Lacaille JC, Gkogkas CG, et al. (2017) Metformin ameliorates core deficits in a mouse model of fragile $X$ syndrome. Nat Med 23:674-677.

Ghittoni R, Patrussi L, Pirozzi K, Pellegrini M, Lazzerini PE, Capecchi PL, Pasini FL, Baldari CT (2005) Simvastatin inhibits T-cell activation by selectively impairing the function of Ras superfamily GTPases. FASEB J 19:605-607.

Ghittoni R, Napolitani G, Benati D, Ulivieri C, Uliveri C, Patrussi L, Laghi Pasini F, Lanzavecchia A, Baldari CT (2006) Simvastatin inhibits the MHC class II pathway of antigen presentation by impairing Ras superfamily GTPases. Eur J Immunol 36:2885-2893.

Ghosh A, Roy A, Matras J, Brahmachari S, Gendelman HE, Pahan K (2009) Simvastatin inhibits the activation of p21ras and prevents the loss of dopaminergic neurons in a mouse model of Parkinson's disease. J Neurosci 29:13543-13556.

Gkogkas CG, Khoutorsky A, Cao R, Jafarnejad SM, PragerKhoutorsky M, Giannakas N, Kaminari A, Fragkouli A, Nader K, Price TJ, Konicek BW, Graff JR, Tzinia AK, Lacaille JC, Sonenberg N (2014) Pharmacogenetic inhibition of elF4E-dependent Mmp9 mRNA translation reverses fragile $X$ syndrome-like phenotypes. Cell Rep 9:1742-1755.

Goswami S, Cavalier S, Sridhar V, Huber KM, Gibson JR (2019) Local cortical circuit correlates of altered EEG in the mouse model of Fragile X syndrome. Neurobiol Dis 124:563-572.

Gross C, Chang CW, Kelly SM, Bhattacharya A, McBride SM, Danielson SW, Jiang MQ, Chan CB, Ye K, Gibson JR, Klann E,
Jongens TA, Moberg KH, Huber KM, Bassell GJ (2015) Increased expression of the PI3K enhancer PIKE mediates deficits in synaptic plasticity and behavior in fragile X syndrome. Cell Rep 11:727-736.

Guillén C, de Gortázar AR, Esbrit P (2004) The interleukin-6/soluble interleukin-6 receptor system induces parathyroid hormone-related protein in human osteoblastic cells. Calcif Tissue Int 75:153-159.

Henderson C, Wijetunge L, Kinoshita MN, Shumway M, Hammond RS, Postma FR, Brynczka C, Rush R, Thomas A, Paylor R, Warren ST, Vanderklish PW, Kind PC, Carpenter RL, Bear MF, Healy AM (2012) Reversal of disease-related pathologies in the fragile $X$ mouse model by selective activation of GABAB receptors with arbaclofen. Sci Transl Med 4:152ra128.

Huo XL, Min JJ, Pan CY, Zhao CC, Pan LL, Gui FF, Jin L, Wang XT (2014) Efficacy of lovastatin on learning and memory deficits caused by chronic intermittent hypoxia-hypercapnia: through regulation of NR2B-containing NMDA receptor-ERK pathway. PLoS One 9:e94278.

Kang S, Kim ES, Moon A (2009) Simvastatin and lovastatin inhibit breast cell invasion induced by H-Ras. Oncol Rep 21:1317-1322.

Khanzada UK, Pardo OE, Meier C, Downward J, Seckl MJ, Arcaro A (2006) Potent inhibition of small-cell lung cancer cell growth by simvastatin reveals selective functions of Ras isoforms in growth factor signalling. Oncogene 25:877-887.

Krab LC, de Goede-Bolder A, Aarsen FK, Pluijm SM, Bouman MJ, van der Geest JN, Lequin M, Catsman CE, Arts WF, Kushner SA, Silva AJ, de Zeeuw Cl, Moll HA, Elgersma Y (2008) Effect of simvastatin on cognitive functioning in children with neurofibromatosis type 1: a randomized controlled trial. JAMA 300:287-294.

Lee J, Lee I, Han B, Park JO, Jang J, Park C, Kang WK (2011) Effect of simvastatin on cetuximab resistance in human colorectal cancer with KRAS mutations. J Natl Cancer Inst 103:674-688.

Li W, Cui Y, Kushner SA, Brown RA, Jentsch JD, Frankland PW, Cannon TD, Silva AJ (2005) The HMG-CoA reductase inhibitor lovastatin reverses the learning and attention deficits in a mouse model of neurofibromatosis type 1. Curr Biol 15:1961-1967.

Liao JK (2005) Clinical implications for statin pleiotropy. Curr Opin Lipidol 16:624-629.

Ling Q, Tejada-Simon MV (2016) Statins and the brain: New perspective for old drugs. Prog Neuropsychopharmacol Biol Psychiatry 66:80-86.

Liu ZH, Chuang DM, Smith CB (2011) Lithium ameliorates phenotypic deficits in a mouse model of fragile $X$ syndrome. Int $\mathrm{J}$ Neuropsychopharmacol 14:618-630.

Liu ZH, Huang T, Smith CB (2012) Lithium reverses increased rates of cerebral protein synthesis in a mouse model of fragile $X$ syndrome. Neurobiol Dis 45:1145-1152.

Mainberger $\mathrm{F}$, Jung $\mathrm{NH}$, Zenker M, Wahllander U, Freudenberg L, Langer S, Berweck S, Winkler T, Straube A, Heinen F, Granstrom S, Mautner VF, Lidzba K, Mall V (2013) Lovastatin improves impaired synaptic plasticity and phasic alertness in patients with neurofibromatosis type 1. BMC neurology 13:131.

McFarland AJ, Anoopkumar-Dukie S, Arora DS, Grant GD, McDermott CM, Perkins AV, Davey AK (2014) Molecular mechanisms underlying the effects of statins in the central nervous system. Int J Mol Sci 15:20607-20637.

Mendola CE, Backer JM (1990) Lovastatin blocks N-ras oncogeneinduced neuronal differentiation. Cell Growth Differ 1:499-502.

Michalon A, Sidorov M, Ballard TM, Ozmen L, Spooren W, Wettstein JG, Jaeschke G, Bear MF, Lindemann L (2012) Chronic pharmacological mGlu5 inhibition corrects fragile $X$ in adult mice. Neuron 74:49-56.

Miura S, Matsuo Y, Saku K (2004) Simvastatin suppresses coronary artery endothelial tube formation by disrupting Ras/Raf/ERK signaling. Atherosclerosis 175:235-243.

Moazen-Zadeh E, Shirzad F, Karkhaneh-Yousefi MA, Khezri R, Mohammadi MR, Akhondzadeh S (2018) Simvastatin as an Adjunctive Therapy to Risperidone in Treatment of Autism: A Randomized, Double-Blind, Placebo-Controlled Clinical Trial. J Child Adolesc Psychopharmacol 28:82-89. 
Muscas M, Louros SR, Osterweil EK (2019) Lovastatin, not simvastatin, corrects core phenotypes in the fragile $X$ mouse model. eNeuro 6.

Nair AB, Jacob S (2016) A simple practice guide for dose conversion between animals and human. J Basic Clin Pharm 7:27-31.

Nürenberg G, Volmer DA (2012) The analytical determination of isoprenoid intermediates from the mevalonate pathway. Anal Bioanal Chem 402:671-685.

Ogunwobi OO, Beales IL (2008) Statins inhibit proliferation and induce apoptosis in Barrett's esophageal adenocarcinoma cells. Am J Gastroenterol 103:825-837.

Osterweil EK, Krueger DD, Reinhold K, Bear MF (2010) Hypersensitivity to mGluR5 and ERK1/2 leads to excessive protein synthesis in the hippocampus of a mouse model of fragile $X$ syndrome. J Neurosci 30:15616-15627.

Osterweil EK, Chuang SC, Chubykin AA, Sidorov M, Bianchi R, Wong RK, Bear MF (2013) Lovastatin corrects excess protein synthesis and prevents epileptogenesis in a mouse model of fragile $X$ syndrome. Neuron 77:243-250.

Ottenhoff MJ, Krab LC, Elgersma Y (2020) Considerations for clinical Therapeutic development of statins for neurodevelopmental disorders. eNeuro 7: ENEURO.0392-19.2020.

Pacey LK, Heximer SP, Hampson DR (2009) Increased GABA(B) receptor-mediated signaling reduces the susceptibility of fragile $X$ knockout mice to audiogenic seizures. Mol Pharmacol 76:18-24.

Parent MA, Hottman DA, Cheng S, Zhang W, McMahon LL, Yuan LL, Li L (2014) Simvastatin treatment enhances NMDAR-mediated synaptic transmission by upregulating the surface distribution of the GluN2B subunit. Cell Mol Neurobiol 34:693-705.

Payne JM, Barton B, Ullrich NJ, Cantor A, Hearps SJC, Cutter G, Rosser T, Walsh KS, Gioia GA, Wolters PL, Tonsgard J, Schorry E, Viskochil D, Klesse L, Fisher M, Gutmann DH, Silva AJ, Hunter SJ, Rey-Casserly C, Cantor NL, et al. (2016) Randomized placebocontrolled study of lovastatin in children with neurofibromatosis type 1. Neurology 87:2575-2584.

Pellerin D, Çaku A, Fradet M, Bouvier P, Dubé J, Corbin F (2016) Lovastatin corrects ERK pathway hyperactivation in fragile $X$ syndrome: potential of platelet's signaling cascades as new outcome measures in clinical trials. Biomarkers 21:497-412.

Ponce J, de la Ossa NP, Hurtado O, Millan M, Arenillas JF, Dávalos A, Gasull T (2008) Simvastatin reduces the association of NMDA receptors to lipid rafts: a cholesterol-mediated effect in neuroprotection. Stroke 39:1269-1275.

Protic D, Salcedo-Arellano MJ, Dy JB, Potter LA, Hagerman RJ (2019) New targeted treatments for fragile $X$ syndrome. Curr Pediatr Rev 15:251-258.

Provenzano G, Pangrazzi L, Poli A, Pernigo M, Sgado P, Genovesi S, Zunino G, Berardi N, Casarosa S, Bozzi Y (2014) Hippocampal dysregulation of neurofibromin-dependent pathways is associated with impaired spatial learning in engrailed 2 knock-out mice. J Neurosci 34:13281-13288.

Ronesi JA, Collins KA, Hays SA, Tsai NP, Guo W, Birnbaum SG, Hu JH, Worley PF, Gibson JR, Huber KM (2012) Disrupted Homer scaffolds mediate abnormal mGluR5 function in a mouse model of fragile X syndrome. Nat Neurosci 15:431-440.

Roy A, Jana M, Kundu M, Corbett GT, Rangaswamy SB, Mishra RK, Luan CH, Gonzalez FJ, Pahan K (2015) HMG-CoA reductase inhibitors bind to PPAR $\alpha$ to upregulate neurotrophin expression in the brain and improve memory in mice. Cell Metab 22:253-265.

Santa-Catalina MO, Garcia-Marin LJ, Bragado MJ (2008) Lovastatin effect in rat neuroblasts of the CNS: inhibition of cap-dependent translation. J Neurochem 106:1078-1091.

Schachter M (2005) Chemical, pharmacokinetic and pharmacodynamic properties of statins: an update. Fundam Clin Pharmacol 19:117-125
Schaefer EJ, McNamara JR, Tayler T, Daly JA, Gleason JL, Seman LJ, Ferrari A, Rubenstein JJ (2004) Comparisons of effects of statins (atorvastatin, fluvastatin, lovastatin, pravastatin, and simvastatin) on fasting and postprandial lipoproteins in patients with coronary heart disease versus control subjects. Am J Cardiol 93:31-39.

Schafer WR, Kim R, Sterne R, Thorner J, Kim SH, Rine J (1989) Genetic and pharmacological suppression of oncogenic mutations in ras genes of yeast and humans. Science 245:379-385.

Sidorov MS, Krueger DD, Taylor M, Gisin E, Osterweil EK, Bear MF (2014) Extinction of an instrumental response: a cognitive behavioral assay in Fmr1 knockout mice. Genes Brain Behav 13:451458.

Stivaros S, Garg S, Tziraki M, Cai Y, Thomas O, Mellor J, Morris AA, Jim C, Szumanska-Ryt K, Parkes LM, Haroon HA, Montaldi D, Webb N, Keane J, Castellanos FX, Silva AJ, Huson S, Williams S, Evans DG, Emsley R et al. (2018) Randomised controlled trial of simvastatin treatment for autism in young children with neurofibromatosis type 1 (SANTA). Mol Autism 9:12.

Stoppel LJ, Osterweil EK, Bear MF (2017) The mGluR theory from mice to men. In: Fragile $X$ syndrome: from genetics to targeted treatment. (Willemsen R, Kooy F, eds). San Diego: Elsevier.

Sundararaj KP, Samuvel DJ, Li Y, Nareika A, Slate EH, Sanders JJ, Lopes-Virella MF, Huang Y (2008) Simvastatin suppresses LPS-induced MMP-1 expression in U937 mononuclear cells by inhibiting protein isoprenylation-mediated ERK activation. J Leukoc Biol 84:1120-1129.

Takayama N, Kai H, Kudo H, Yasuoka S, Mori T, Anegawa T, Koga M, Kajimoto H, Hirooka Y, Imaizumi T (2011) Simvastatin prevents large blood pressure variability induced aggravation of cardiac hypertrophy in hypertensive rats by inhibiting RhoA/Ras-ERK pathways. Hypertens Res 34:341-347.

Thomson SR, Seo SS, Barnes SA, Louros SR, Muscas M, Dando O, Kirby C, Wyllie DJA, Hardingham GE, Kind PC, Osterweil EK (2017) Cell-type-specific translation profiling reveals a novel strategy for treating fragile $X$ syndrome. Neuron 95:550-563. e5.

Thurman AJ, Potter LA, Kim K, Tassone F, Banasik A, Potter SN, Bullard L, Nguyen V, McDuffie A, Hagerman R, Abbeduto L (2020) Controlled trial of lovastatin combined with an open-label treatment of a parent-implemented language intervention in youth with fragile X syndrome. J Neurodev Disord 12:12.

Tuckow AP, Jefferson SJ, Kimball SR, Jefferson LS (2011) Simvastatin represses protein synthesis in the muscle-derived $\mathrm{C}$ (2) C(1)(2) cell line with a concomitant reduction in eukaryotic initiation factor 2B expression. Am J Physiol Endocrinol Metab 300: E564-E570.

Ullrich NJ, Payne JM, Walsh KS, Cutter G, Packer R, North K, ReyCasserly C, Consortium NFCT (2020) Visual spatial learning outcomes for clinical trials in neurofibromatosis type 1. Ann Clin Transl Neurol 7:245-249.

van der Vaart $T$, Plasschaert $E$, Rietman $A B$, Renard $M$, Oostenbrink R, Vogels $A$, de Wit MC, Descheemaeker MJ, Vergouwe $\mathrm{Y}$, Catsman-Berrevoets CE, Legius E, Elgersma $\mathrm{Y}$, Moll HA (2013) Simvastatin for cognitive deficits and behavioural problems in patients with neurofibromatosis type 1 (NF1SIMCODA): a randomised, placebo-controlled trial. Lancet Neurol 12:1076-1083.

Yan QJ, Rammal M, Tranfaglia M, Bauchwitz RP (2005) Suppression of two major fragile $X$ syndrome mouse model phenotypes by the mGluR5 antagonist MPEP. Neuropharmacology 49:1053-1066.

Zacco A, Togo J, Spence K, Ellis A, Lloyd D, Furlong S, Piser T (2003) 3-hydroxy-3-methylglutaryl coenzyme A reductase inhibitors protect cortical neurons from excitotoxicity. J Neurosci 23:11104-11111. 